\title{
Real-time imaging of gene promoter activity using an adenoviral reporter construct demonstrates transcriptional dynamics in normal anterior pituitary cells
}

\author{
J A Stirland, Z C Seymour ${ }^{1}$, S Windeatt ${ }^{2}$, A J Norris ${ }^{2}$, P Stanley ${ }^{2}$, \\ M G Castro ${ }^{2}$, A S I Loudon, M R H White ${ }^{1}$ and J R E Davis ${ }^{2}$ \\ School of Biological Sciences, University of Manchester, Manchester M13 9PT, UK \\ ${ }^{1}$ Centre for Cell Imaging, School of Biological Sciences, University of Liverpool, Liverpool L69 7ZB, UK \\ ${ }^{2}$ School of Medicine, University of Manchester, Manchester M13 9PT, UK \\ M G Castro is now at Gene Therapeutics Research Institute, Cedars Sinai Medical Center, Department of Medicine, UCLA, Research Pavilion, Room 5090, \\ 8700 Beverly Boulevard, Los Angeles, California 90048, USA \\ (Requests for offprints should be addressed to J R E Davis; Email: julian.davis@man.ac.uk)
}

\begin{abstract}
Although analysis of luciferase activity using luminescence imaging has provided new insights into the dynamic regulation of gene expression in living tissues, studies in vitro have relied on stably transfected clonal cell lines, limiting the choice of cell type and species, or DNA microinjection, which is arduous and highly selective. We report here the first use of a recombinant adenovirus in which the firefly luciferase reporter gene was regulated by the prolactin gene promoter, to study temporal dynamics of promoter activity. This vector was used to infect the pituitary GH3 cell line, and also primary cultures of Syrian hamster pituitary cells. We show that adenovirally transduced cells retained normal regulation of the promoter-
\end{abstract}

reporter transgene by appropriate signals. Furthermore, microscopic imaging studies indicated that both clonal and primary pituitary cells were transduced efficiently, giving readily detectable luminescence signals in real-time over long periods. Finally, analysis of single-cell expression patterns indicated that prolactin promoter activity was highly dynamic with pulses in gene expression, revealing that the transcriptional instability seen in clonal cells is a feature of normal pituitary cells. Adenoviral vectors offer a valuable tool for studies of gene regulation where conventional transgenesis and clonal cell lines are not available.

Journal of Endocrinology (2003) 178, 61-69

\section{Introduction}

Reporter genes have been widely used in studies of mechanisms of gene regulation in cultured cells in vitro, but until recently very little has been known of the temporal patterns of promoter activation in normal tissues studied in real-time. The firefly luciferase reporter gene has become widely used for assays of promoter function, and its activity can be monitored by microscopic luminescence imaging (White et al. 1990, 1995, Craig et al. 1991, Rutter et al. 1998). Using real-time microscopic imaging of a stably transfected rat pituitary cell line, we have recently demonstrated that prolactin (PRL) promoter activity in individual living cells is not stable and exhibits unexpected 40-fold fluctuations from hour to hour (Takasuka et al. 1998). Although different individual cells display markedly different mRNA content and peptide secretion rates as determined by in situ hybridization and haemolytic plaque assays (Hofland et al. 1991), our data indicated that this heterogeneity is subject to rapid dynamic change (Takasuka et al. 1998). The mechanisms for the instability of PRL gene transcription are unknown, but recent imaging and biochemical data indicate that nuclear hormone receptors are recruited to and released from chromatin very rapidly in response to hormonal signals (McNally et al. 2000, Shang et al. 2000). This leads to the conclusion that transcriptional regulation may be highly dynamic, and the inherent instability of this process may be an important aspect of endocrine regulation.

To date our studies have relied on stably transfected cell lines (Takasuka et al. 1998, McFerran et al. 2001, Norris et al. 2003), but it is vital that this work be extended to normal cells, to allow better understanding of physiological processes, and applied to other species. Pioneering studies using microinjection of individual pituitary cells have revealed important information about pituitary gene regulation in relation to endocrine signals (Castano et al. 1996, Villalobos et al. 1998), but the microinjection procedure is technically difficult and inevitably entails the selection of a small number of cells for any given experiment. In an 
attempt to develop an alternative approach, with wider application for species in which conventional transgenesis is not yet established, we developed a viral vector to deliver reporter genes efficiently into primary cells (Castro et al. 1997, Stone et al. 2000). We have used a recombinant adenovirus (RAd) containing a transcription unit in which the luciferase reporter gene is regulated by a $4400 \mathrm{bp}$ PRL gene promoter fragment. Here, we describe the first use of an adenoviral vector to investigate dynamic temporal regulation of gene promoter activity in primary cells in culture. We used as a model anterior pituitary cells from the Syrian hamster, a seasonal mammal that exhibits major changes in PRL gene expression under different photoperiodic conditions, and our previous work has demonstrated marked heterogeneity of response of lactotrophic cells to intra-pituitary secretagogues (Stirland et al. 2001).

\section{Materials and Methods}

\section{Development of PRL-luciferase adenoviral reporter vector}

We generated an RAd based on Ad type 5, in which the $\mathrm{E} 1$ region and part of the $\mathrm{E} 3$ region were deleted, and into which we cloned a luciferase reporter gene linked to $\mathrm{a}-4429 /+14$ bp human PRL promoter fragment (RAdhPRL-luc). Briefly, a 6081 bp PRL-luc cassette was excised from the p5000/PRL-luc ${ }^{+}$plasmid (Takasuka et al. 1998) using an XbaI digest. This fragment was cloned into the $\mathrm{XbaI}$ site in the $\mathrm{p} \Delta \mathrm{E} 1 \mathrm{sp} 1 \mathrm{a}$ shuttle plasmid (Microbix Biosystems, Toronto, ON, Canada). This shuttle vector was co-transfected with pBHG10 (containing the rest of the adenoviral genome) into the 293 cell line, which expresses the E1 protein and allows propagation of the RAd, as previously described (Shering et al. 1997, Southgate et al. 2000).

\section{Cell culture}

All animal procedures were performed in accordance with the UK Animals (Scientific Procedures) Act of 1986. Primary pituitary cell cultures were prepared from male Syrian hamsters (9-12 weeks of age; University of Manchester breeding colony), as described previously (Stirland et al. 2001). Briefly, the pars distalis (PD) region of the anterior pituitary gland was dissected and fragments were washed and dispersed enzymatically using collagenase (Life Technologies, Inc., Paisley, Strathclyde, UK) and DNase I (Sigma Chemical Co., Poole, Dorset, UK). Cell yield was routinely $0.45 \pm 0.06 \times 10^{6}$ cells/pituitary gland (mean \pm S.E.M.), and viability exceeded $85 \%$. Cells were cultured in Dulbecco's modified Eagle's medium (DMEM; Life Technologies) with $25 \mathrm{mM}$ Hepes (Sigma), supplemented with $10 \%$ fetal calf serum (FCS; Harlan Sera-Lab Ltd, Loughborough, Leics, UK), $4 \mathrm{mM}$ L-glutamine, $1 \mathrm{mM}$ sodium pyruvate and $1 \%$ penicillinstreptomycin (Life Technologies).
The rat pituitary GH3 cell line was obtained from the European Collection of Animal Cell Cultures (ECACC, Salisbury, Wilts, UK) and cultured in DMEM with 10\% FCS as before (Takasuka et al. 1998). These cells were used for comparisons with adenovirus-infected GH3 cells and primary cells.

\section{Luciferase assays of adenovirus-infected pituitary cell lysates}

Primary pituitary cells were plated at $4-5 \times 10^{4}$ cells/well in 24-well tissue culture plates (Costar UK Ltd, High Wycombe, Bucks, UK), and cultured for 3 or 8 days at $37^{\circ} \mathrm{C}$ in $5 \% \mathrm{CO}_{2}$, then washed and recounted, before adenoviral infection. Pituitary GH3 cells were plated at $2-5 \times 10^{4}$ cells/well for 3 days, washed and recounted, before infection. For initial experiments to optimize adenoviral transduction with RAd-hPRL-luc, cells were infected with a range of different multiplicity of infections (MOIs, i.e. infective virus particles per cell) from 0-300 for 2 or 3 days before cell lysis for determination of luciferase activity. For experiments with effectors, both GH3 cells and PD cells were infected at MOI 30 for $30 \mathrm{~h}$, and the medium was then changed to serum-free (DMEM with $0 \cdot 25 \% \mathrm{BSA}$ ) medium for a further $17 \mathrm{~h}$ prior to the experiment. Cells were then incubated with forskolin (Sigma), an activator of the cAMP signalling pathway, and/or the glucocorticoid, dexamethasone (Sigma), for $8 \mathrm{~h}$ before cell lysis. Cell lysates were prepared and luciferase activity measured over a $2 \mathrm{~s}$ period in the presence of luciferin and ATP (Sigma), as a measure of PRL promoter activity in RAd-infected cells, using a Berthold-Lumat LB9501 luminometer (Berthold-Lumat, St Albans, Herts, UK), all as previously described (Stirland et al. 2001).

\section{Microscopic imaging of individual living pituitary cells}

Imaging experiments were performed as previously described (Takasuka et al. 1998, McFerran et al. 2001, Norris et al. 2003). Cells were seeded $\left(5 \times 10^{4}\right.$ and $1 \times 10^{5}$ cells/dish for GH3 and primary PD cells respectively) onto $35 \mathrm{~mm}$ coverslip dishes (MatTek Corp., Ashland, MA, USA) which had been pretreated with 0.1 or $0.25 \mathrm{mg} / \mathrm{ml}$ poly-L-lysine (Sigma), and cultured for 3 days in DMEM $+10 \%$ FCS medium at $37{ }^{\circ} \mathrm{C}, 5 \% \mathrm{CO}_{2}$ before infection with RAd-hPRL-luc at MOI 30. After a further incubation period $(30-47 \mathrm{~h})$, cells were transferred to a heated stage of a Zeiss-Axiovert microscope (Carl Zeiss, Welwyn Garden City, Herts, UK) in a humidified $37^{\circ} \mathrm{C}$ chamber in $5 \% \mathrm{CO}_{2}$ for the remainder of the experiment. Luciferin (1 mM; Bio-Synth, Inc., Staad, Switzerland) was added at the start of the experiment.

Luminescence imaging employed a Hamamatsu VIM photon-counting CCD camera $(\times 10,0.5$ numerical aperture objective) (Hamamatsu, Hamamatsu City, Japan) and output was analysed with Argus-50 software (Hamamatsu). Bright-field images were taken using 
differential interference contrast to allow localization of the cells. Images were collected using $30 \mathrm{~min}$ integration times at $30 \mathrm{~min}$ or $1 \mathrm{~h}$ intervals. Centre of gravity images were used for quantification, using either total photon counts from the whole field or photon counts derived from defined cellular areas (325 pixels). Hormonal stimulation of cells commenced at least $15 \mathrm{~h}$ after addition of luciferin to allow luciferase activity to fall to a steady baseline (Takasuka et al. 1998, McFerran et al. 2001, Norris et al. 2003). Forskolin was used at a final concentration of $5 \mu \mathrm{M}$, and a luciferin concentration of $1 \mathrm{mM}$ was used in all experiments.

\section{Quantification and analysis}

Data from the 24-well experiments were analysed by one-way ANOVA, followed by post-hoc comparison by Newman-Keuls multiple comparison test. Results are presented as the means \pm S.E.M. Differences of $P<0.05$ were considered statistically significant. For analysis of temporal patterns of promoter activity, cluster analysis (Veldhuis \& Johnson 1986) was used to determine statistically significant pulses of gene expression, and approximate entropy (ApEn) analysis (Hartman et al. 1994) was used to test for the degree of randomness in the fluctuations observed, as previously described (McFerran et al. 2001). Data were analysed using the SPSS computer program.

\section{Results}

\section{Validation of viral transduction}

In initial experiments, RAd-PRL-luc vectors were tested in the rat GH3 pituitary cell line, and then in primary cultures of hamster pituitary PD cells. Cells were infected with increasing amounts of vector (MOI) and luciferase expression measured by luminometric assays of cell lysates (Fig. 1). The optimal MOI differed according to cell type: high MOIs appeared to reduce transgene expression in GH3 cells but not primary PD cells. Luciferase activity was normally higher in the transduced GH3 cells than the PD cells, but this may partly reflect the restriction of reporter gene expression by the PRL promoter to just the lactotrophic cells among the mixed cell populations in primary pituitary cultures, whereas in the clonal somatolactotrophic GH3 cell line, all of the cells are capable of activating the transgene (Southgate et al. 2000, Davis et al. 2001, Smith-Arica et al. 2001). From these experiments, an MOI of 30 was selected for subsequent studies.

\section{Hormonal regulation of the adenovirally transduced promoter-reporter construct}

The behaviour of the PRL promoter in the context of the adenoviral vector was tested using a series of known regulators of PRL promoter activity (Berwaer et al. 1991),

\section{A GH3 cells}

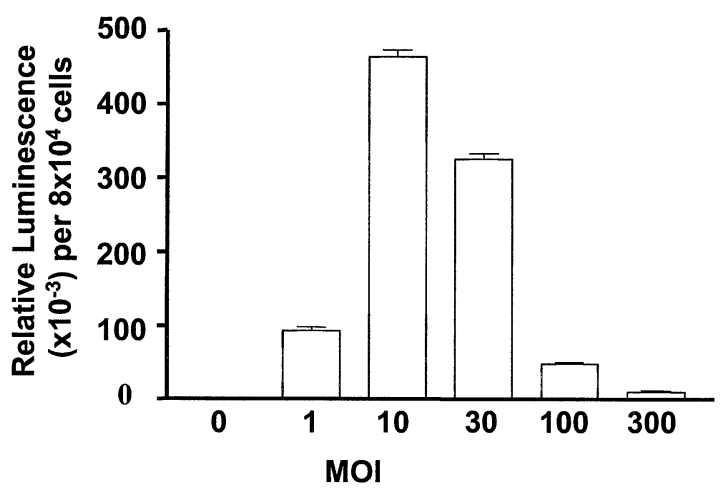

B Primary pituitary cells

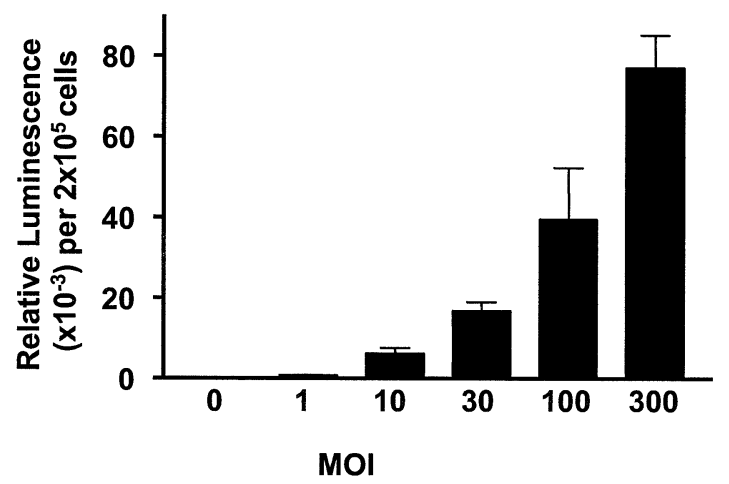

Figure 1 Effect of $\mathrm{MOI}$ on luminescence in (A) clonal $\mathrm{GH} 3$ pituitary cells and (B) primary hamster pituitary cells in culture. (A) Pituitary GH3 cells were cultured for 3 days, washed and recounted, and infected with RAd-PRL-luc at MOls of 0-300. After $72 \mathrm{~h}$, infected cells were washed and lysates assayed for determination of luciferase activity. Data are means \pm S.E.M, $n=3$. (B) Primary hamster pituitary PD cells were cultured for 8 days, washed and recounted, and infected with RAd-PRL-luc at MOls of 0-300, with triplicate wells per MOI. After $53 \mathrm{~h}$, cells were

washed and lysates assayed for determination of luciferase activity. Data are means \pm S.E.M., $n=3$.

to confirm that the transgene expression was behaving in an appropriate manner. A series of agents were tested in both GH3 cells and primary PD cells after adenoviral infection. Forskolin induced a dose-dependent 3- to 4-fold induction of PRL promoter activity, and dexamethasone inhibited this induction, as previously found in transient expression studies (Berwaer et al. 1991) (Fig. 2). The PRL secretagogues thyrotrophin-releasing hormone and basic fibroblast growth factor also induced luciferase expression in a dose-dependent manner, as expected (data not shown). We also found reproducible inductions in PRL promoter activity in both adenovirus-infected GH3 cells 
A GH3 cells

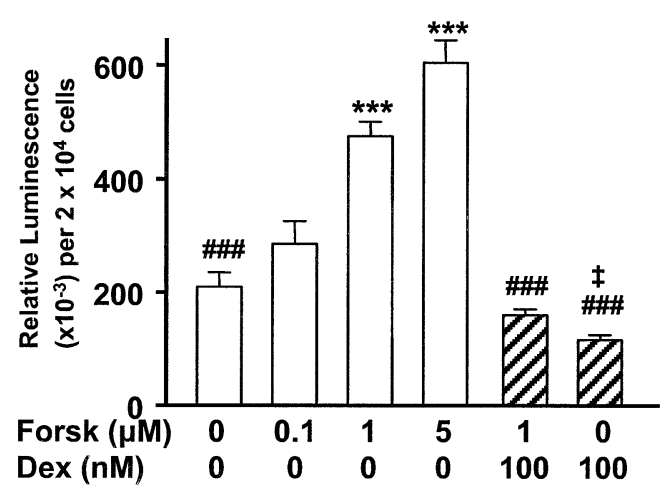

\section{B Primary cells}

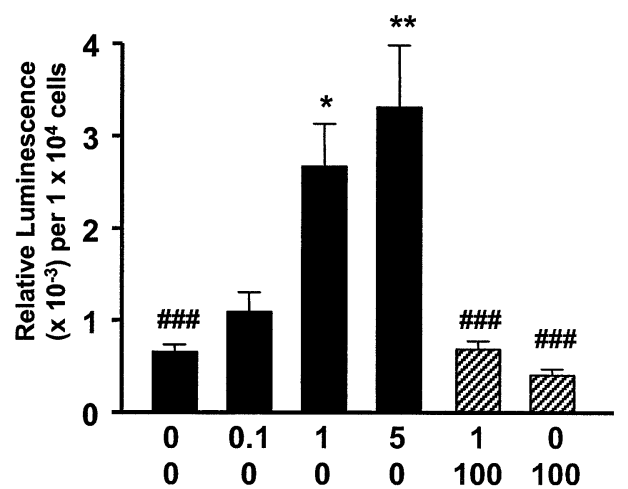

Figure 2 Dose responses of adenovirally encoded PRL promoter-luciferase to forskolin and dexamethasone in adenovirus-infected clonal pituitary $\mathrm{GH} 3$ cells and primary hamster pituitary cells in culture. Pituitary GH3 cells (A) or primary hamster pituitary cells (B) were cultured in DMEM with 10\% FCS. After 3 days, cells were washed and re-counted and infected with RAd-PRL-luc at MOI 30. After $30 \mathrm{~h}$, the culture medium was replaced with serum-free DMEM with $0 \cdot 25 \%$ BSA. After a further $17 \mathrm{~h}$ (i.e. $48 \mathrm{~h}$ after infection), cells were incubated with forskolin (forsk, $0-5 \mu \mathrm{M}$ ) and/or dexamethasone (Dex, $100 \mathrm{nM}$ ) for $8 \mathrm{~h}$ and lysates assayed for determination of luciferase activity. Data are means \pm S.E.M., $n=4$ wells per treatment. Forskolin induced PRL promoter activity $\left({ }^{*} P<0 \cdot 05,{ }^{*} P<0 \cdot 01,{ }^{* *} P<0.001\right.$ vs unstimulated cells), and this was

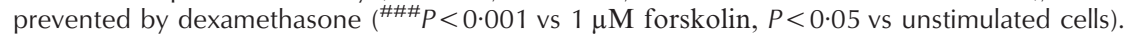

and primary pituitary cells in the presence of conditioned medium from cultures of hamster pituitary pars tuberalis (PT) cells: for primary cultures of RAd-infected hamster PD cells, PT-conditioned medium stimulated PRL promoter activity $1 \cdot 9$-fold $(1938 \pm 146$, vs $1018 \pm 55$ relative luminescence units per $2 \times 10^{4}$ cells, $\left.n=4, P<0 \cdot 001\right)$. This is consistent with our previous observations using a GH3 cell line stably transfected with a hPRL-luc reporter gene construct, and demonstrates that the PT can drive PRL promoter activity in normal lactotrophic cells (Stirland et al. 2001).

\section{Luminescence microscopy of adenoviral luciferase expression:} GH3 cells

The temporal dynamics of PRL promoter activity were then studied by luminescence microscopy in clonal pituitary GH3 cells after infection with RAd-PRL-luc. Luminescence imaging commenced following the addition of luciferin: forskolin $(5 \mu \mathrm{M})$ was added to the culture medium after $23 \mathrm{~h}$, and imaging continued up to $42 \mathrm{~h}$. Microscopic images and quantitative luminescence data are shown in Fig. 3, with a bright-field image shown at the time of luciferin addition. The addition of luciferin generated a transient increase in luminescence, which then settled to steady baseline levels (Fig. 3A). Forskolin treatment generated a sustained rise in luciferase expression in the total population of cells in the microscope field (Fig. 3B). Quantitative analysis revealed that within the overall population most individual cells showed a transient transcriptional response to forskolin, but the temporal patterns of this response varied widely from cell to cell (Fig. 3C and D). This heterogeneity in response is similar to that noted in earlier work using GH3 cells stably transfected with luciferase reporter genes (Takasuka et al. 1998, Norris et al. 2003) and thus confirms that the adenoviral transduction approach reveals similar patterns of transcriptional instability and heterogeneity in normal cells.

Luminescence microscopy of adenoviral luciferase expression: primary PD cells

Following validation in the GH3 cell line, normal hamster pituitary PD cells were studied by luminescence microscopy. Cells were imaged for $30 \mathrm{~h}$ after luciferin

Figure 3 Imaging of PRL promoter-directed luminescence in the adenovirally transduced $\mathrm{GH} 3$ cell line, before and after stimulation with forskolin. Pituitary GH3 cells cultured in DMEM with 10\% FCS for 3 days, washed and recounted, and infected with RAd-PRL-luc at MOI 30. After $30 \mathrm{~h}$, the medium was replaced with serum-free DMEM with $0 \cdot 25 \%$ BSA. After a further $17 \mathrm{~h}$ (i.e. $47 \cdot 0 \mathrm{~h}$ after infection), luciferin $(1 \mathrm{mM})$ was added $(\mathrm{t}=0 \mathrm{~h}$ on panels $\mathrm{A}, \mathrm{C}$ and $\mathrm{D})$. Forskolin $(5 \mu \mathrm{M})$ was added $23 \mathrm{~h}$ after the start of imaging, indicated by horizontal bars in panels C and D. Images were collected ( $\times 10$ objective) over 30 min integration times at $1 \mathrm{~h}$ intervals (A and B). Quantitative data from these images were analysed for 27 single-cell areas in the overall field of cells $(C)$ and for six representative single-cell areas (D). DIC (differential interference contrast) denotes bright-field image. 


\section{A Unstimulated $\mathrm{GH} 3$ cells}
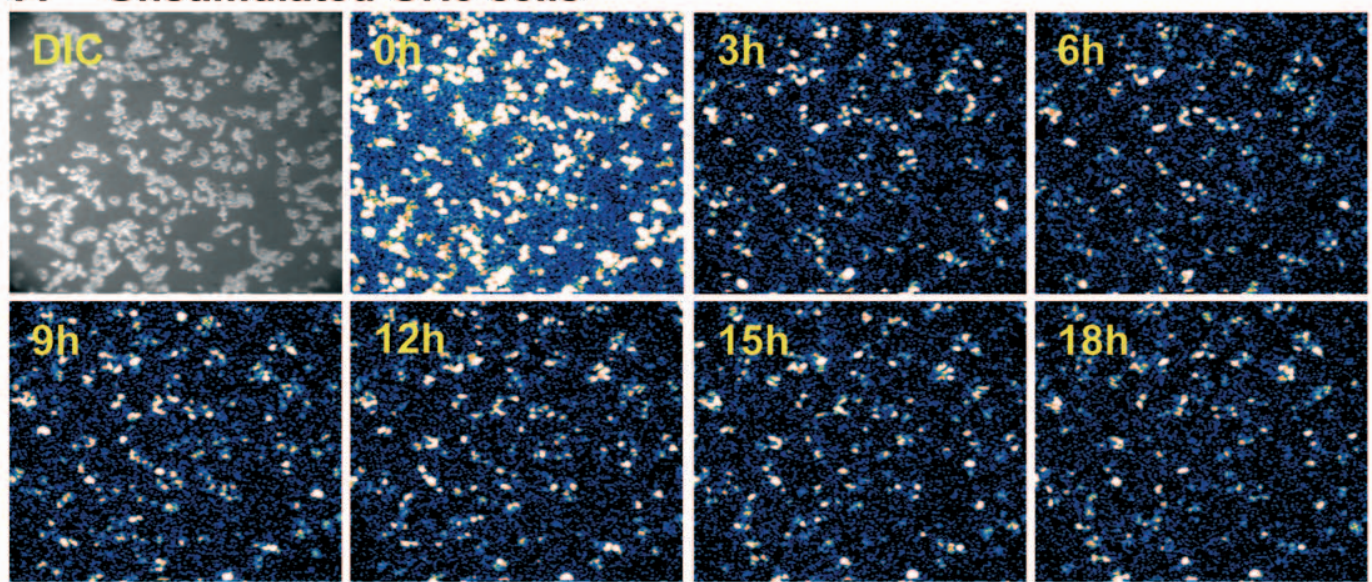

B Stimulation with $5 \mu \mathrm{M}$ Forskolin

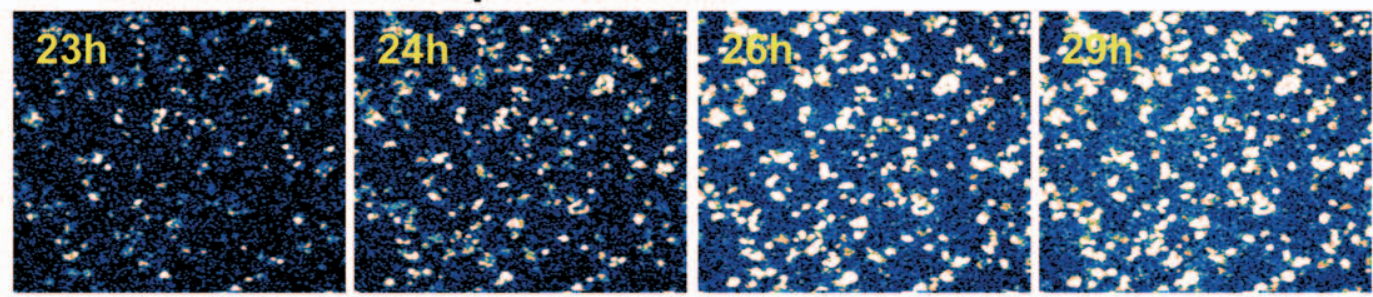

C

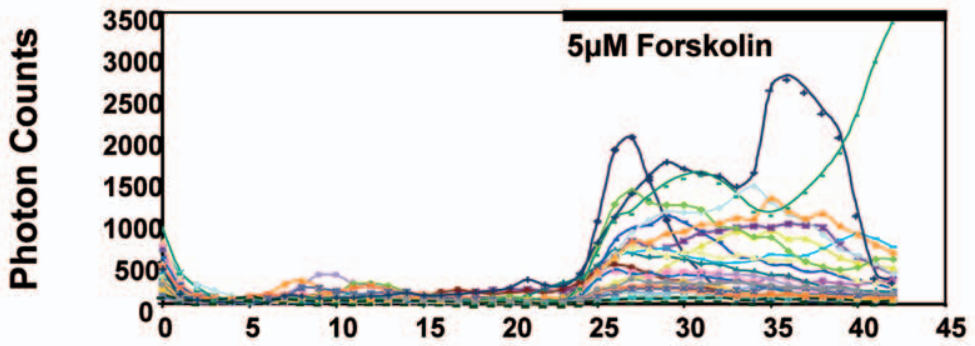

D

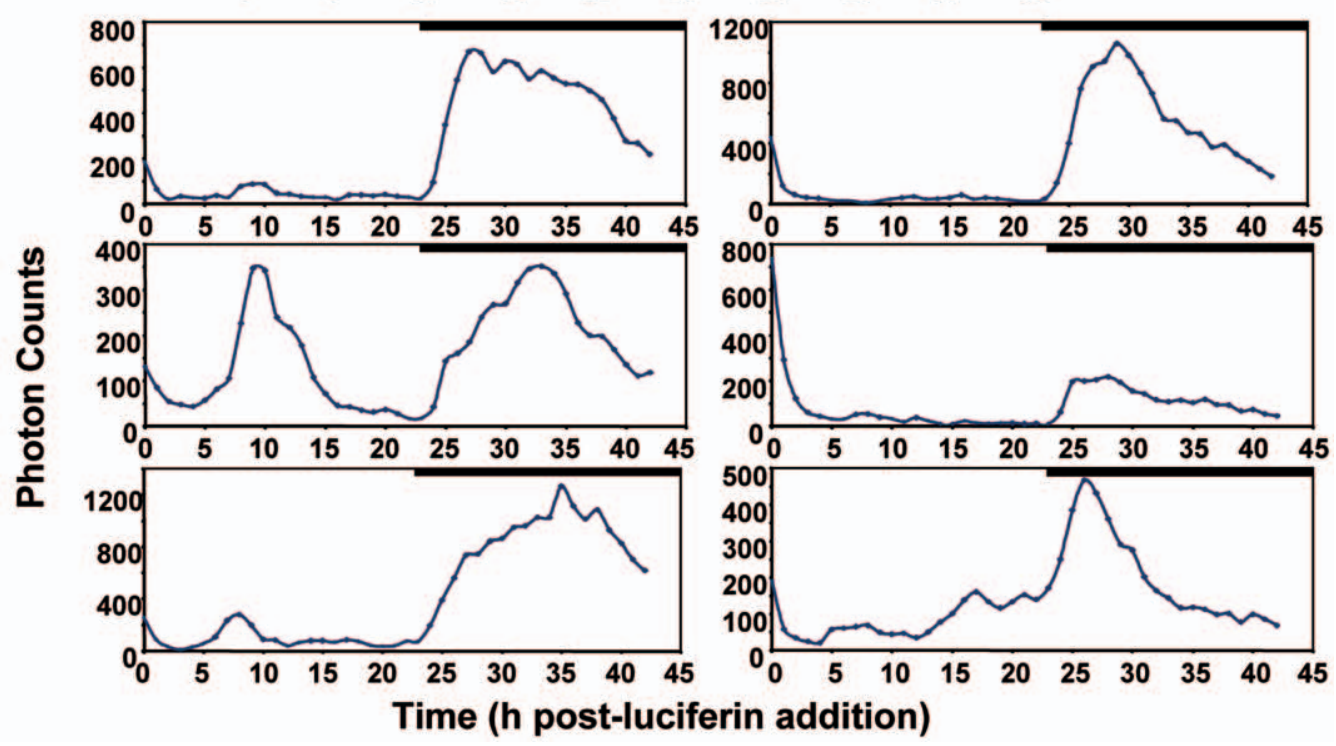


A Unstimulated primary pituitary cells
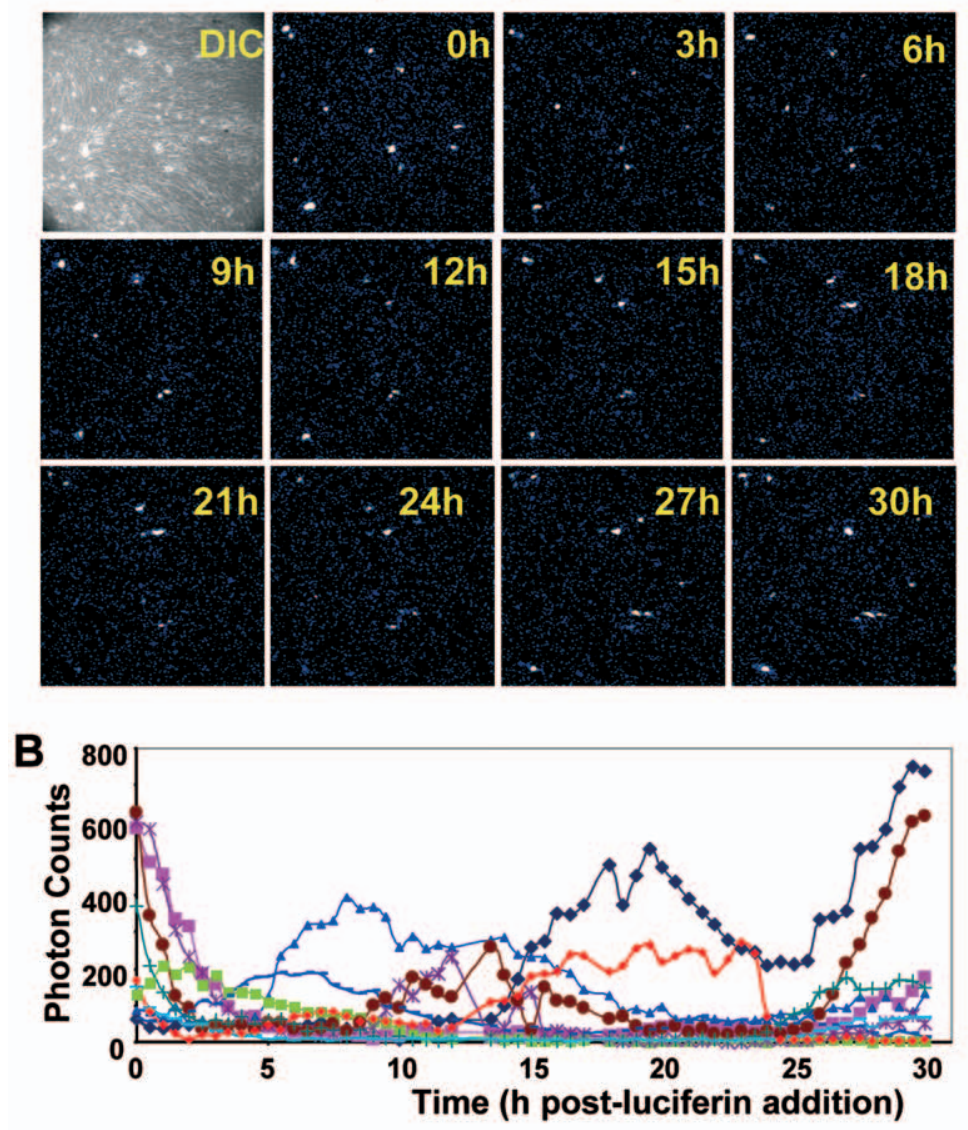

C Stimulation with $5 \mu \mathrm{M}$ forskolin
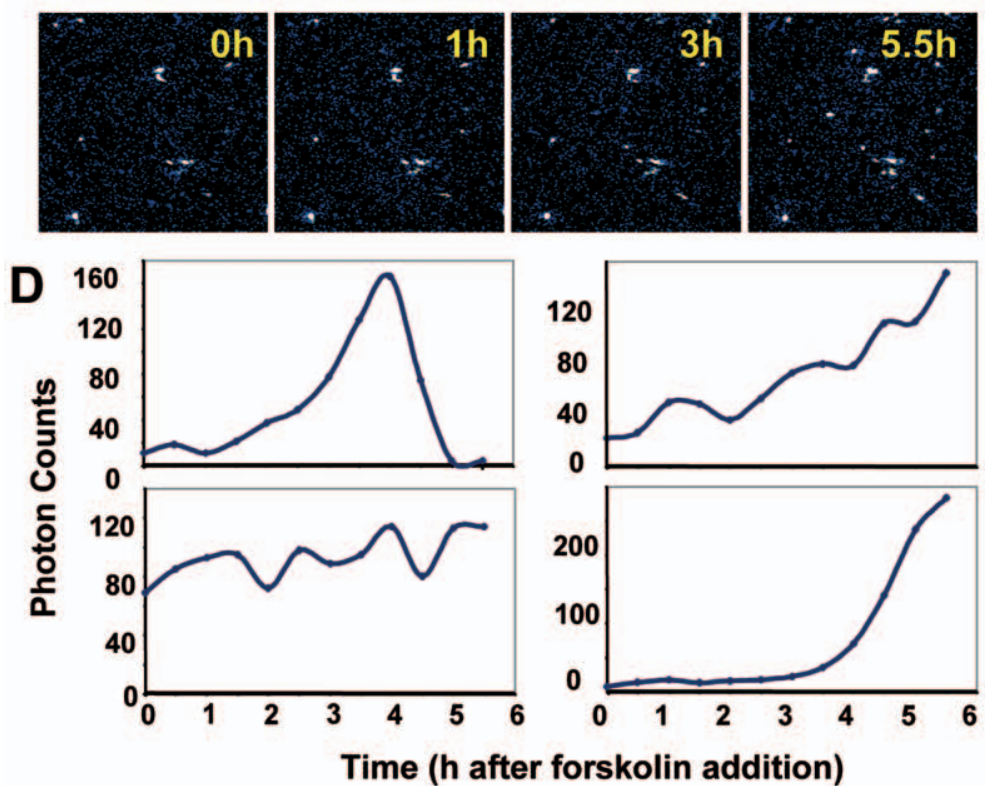
addition, and then for a further $5 \mathrm{~h}$ after forskolin stimulation (Fig. 4A). Marked fluctuations in luciferase activity were noted from hour to hour in unstimulated PD cells, indicating that resting normal pituitary cells display highly dynamic patterns of transcription, as previously seen with stably transfected clonal hPRL-luc/GH3 cells. Oscillating patterns were detectable in over $60 \%$ of cells (representative experiment shown in Fig. 4B). Cluster analysis confirmed that pulses in gene expression were statistically significant, with cells showing between 1 and 4 pulses (mean 1.5) over $30 \mathrm{~h}$. ApEn analysis of the time-series data confirmed that these fluctuations were non-random (ApEn scores $0.71 \pm 0.33$ (mean \pm s.D.), compared with $1.22 \pm 0.23$ for the same data after random shuffling, $P<0 \cdot 001$, indicating significant regularity) (Hartman et al. 1994). After forskolin treatment individual cells displayed heterogeneous patterns of response, some cases showing transient and others sustained responses to identical stimulation (Fig. 4C and D).

\section{Discussion}

Microscopic studies of luciferase reporter gene activation offer valuable insights into dynamic temporal regulation of gene expression, but so far have relied on either clonal cell lines or microinjection of primary cultures of cells (Castano et al. 1996, Takasuka et al. 1998, Villalobos et al. 1998, McFerran et al. 2001, Norris et al. 2003). Our studies demonstrate for the first time that real-time microscopic imaging of promoter activity can also be readily achieved in normal pituitary cells using an RAd expressing the firefly luciferase gene under the control of an appropriate gene promoter. Our results indicate that adenovirus vectors can be used at low copy number, achieving sufficient transgene expression for detectable luciferase activity to be imaged microscopically over long periods. We also show that the appropriate hormonal regulation of the adenoviral transgene is maintained in transduced cells. Our study thus demonstrates that adenoviral vectors offer a highly efficient route towards studies of real-time gene regulation in normal cells.

Adenovirus vectors are characterized by highly efficient gene transfer into target cells, and can transduce a wide range of cell types, including post-mitotic cells (Stone et al. 2000). In the case of the pituitary, the efficacy of adenoviral gene transfer has been demonstrated in a number of studies. All cell types in the mature pituitary gland are effectively transduced by adenoviruses expressing the $\beta$-galactosidase reporter gene (Castro et al. 1997), while pituitary hormone gene promoters are able to restrict transgene expression to specific target cell types, in both clonal cell lines and cultured normal pituitary cells (Lee et al. 1999, Southgate et al. 2000, Davis et al. 2001, Smith-Arica et al. 2001). Adenoviral vectors using the $\beta$-galactosidase reporter gene have been used effectively to report the spatial patterns of transgene expression in different tissues including the pituitary (Lee et al. 1999, Southgate et al. 2000, Windeatt et al. 2000, Davis et al. 2001, Smith-Arica et al. 2001). The luciferase reporter gene, on the other hand, is preferable for quantitative temporal studies of dynamic gene expression, due to its sensitivity and short half-life (White et al. 1995, Takasuka et al. 1998, Villalobos et al. 1998, Norris et al. 2003).

The present data, using the luciferase transgene as a highly sensitive reporter of promoter activity, show that the optimal MOI for infection differed between clonal GH3 cells and primary pituitary cells. The fall in activity using high MOIs in clonal GH3 cells might reflect direct adenovirus toxicity, although previous work suggested this is unlikely (Windeatt et al. 2000); alternatively, it might be due to promoter squelching with higher copy numbers per cell, resulting from competition for limiting amounts of cellular transcription factors and co-activators.

Adenoviral vectors offer a valuable alternative to microinjection, which has until now been the only approach for studying promoter activity in normal cells, other than generating transgenic animals. In particular, the high efficiency of adenoviral transduction allows analysis of the transcriptional patterns of almost all individual cells that contribute to the behaviour of a given population. Although microinjection of reporter gene constructs has been valuable in studies of normal cells from animals in different physiological states (Frawley et al. 1994, Castano et al. 1996, Villalobos et al. 1998), it is laborious and necessarily highly selective for a small number of cells that can be successfully injected amongst the overall population, and usually generates very high transgene copy numbers for a short period. Our studies now show that effective transduction of luciferase activity can be achieved using relatively low copy number, which will be critical for detailed studies of transcriptional regulation where squelching phenomena may seriously compromise interpretation of quantitative effects.

Our data now extend previous information on the temporal regulation of PRL gene promoter activity in individual living cells. Using stably transfected pituitary GH3 cells, we have reported that activity of PRL and

Figure 4 Imaging of PRL promoter-directed luminescence in adenovirally transduced primary hamster pituitary cells, before and after stimulation with forskolin. Primary hamster pituitary cells were cultured in DMEM with $10 \%$ FCS for 3 days, washed and recounted, and infected with RAd-PRL-luc at MOI 30. After $30 \mathrm{~h}$, luciferin $(1 \mathrm{mM})$ was added ( $\mathrm{t}=0 \mathrm{~h}$ on panels $\mathrm{A}$ and $\mathrm{B})$. Cells were imaged using 30 min integration times every 30 min. Forskolin $(5 \mu \mathrm{M})$ was added $35.5 \mathrm{~h}$ after start of imaging ( $\mathrm{t}=0 \mathrm{~h}$ on panels $\mathrm{C}$ and $\mathrm{D})$. Quantitative data from these images are shown for the overall field of unstimulated cells (B), and for four representative single-cell areas following forskolin stimulation (D). DIC denotes bright-field image. 
growth hormone promoters is not stable within any given individual cell, but varies dramatically from hour to hour, with phasic oscillations in activity (Takasuka et al. 1998, Norris et al. 2003). Similar findings have been reported in microinjected primary pituitary cells from lactating rats (Villalobos et al. 1998, Shorte et al. 2001). We have found that periodic oscillations in promoter activity can be seen in cell lines exposed to both pulsed and sustained serum stimulation (McFerran et al. 2001), and a recent report using microinjection studies has analysed the periodic nature of 'pulses' in promoter activity in microinjected normal rat pituitary cells (Shorte et al. 2001). The present data, while not addressing the mechanisms of pulsatile gene expression, confirm that this phenomenon may be ubiquitous, as it is observed in normal cells using the adenovirus reporter system. Inherent transcriptional instability may therefore be a common feature of normal cellular physiology. For example, in the pituitary gland of photoperiodic species such as the hamster, we have found that patterns of transcriptional heterogeneity in PRL gene expression are altered in response to secreted factors from the PT that modulate seasonal neuroendocrine rhythms (Stirland et al. 2001). The present approach offers a route to understanding processes of transcriptional recruitment in tissues exhibiting marked circadian and seasonal rhythmicity in gene expression. Adenovirus-mediated gene expression offers an alternative form of transgenesis in animal species, which could offer valuable physiological models not yet available from conventional transgenic approaches. Furthermore, adenoviruses can also achieve highly efficient gene transfer in intact tissue in vivo after stereotaxic injection, both in the rat (Lee et al. 1999, Southgate et al. 2000) and in large animals such as sheep (Davis et al. 2001).

Recent studies have demonstrated that very large numbers of genes exhibit circadian transcriptional periodicity (Panda et al. 2002). Non-circadian (ultradian) fluctuations in gene transcription (Shorte et al. 2001) may be critical in the endocrine regulation of hormone synthesis. Studies of different systems have indicated that gene transcription within an individual cell can be regulated in either a graded or a stochastic (binary) manner (Hume 2000, Becskei et al. 2001, Biggar \& Crabtree 2001). Stochastic regulation may be particularly important for endocrine tissues that require rapid secretory and hormone-synthetic responses to environmental cues, in addition to their long-term adaptive or trophic responses. It is important now to extend this understanding to normal mammalian cells and tissue, using technologies such as adenoviral gene transfer. Since imaging of luminescence or fluorescence of transgenic or injected reporter proteins is applicable not only to transcriptional regulation but also to intracellular signalling cascades (Zaccolo et al. 2000, Nagai et al. 2001), this now raises the possibility of studying intracellular endocrine physiology in populations of normal cells. Ultimately, such studies could extend to in vivo systems, in which viral gene transfer could be followed by luminescence imaging in the intact animal (Yamaguchi et al. 2001, Wu et al. 2002), providing insight into the temporal regulation of cellular processes during physiological responses at the cellular level.

\section{Acknowledgements}

We are very grateful for financial support from the Biotechnology and Biological Sciences Research Council, the Medical Research Council and the Wellcome Trust. We also thank Hamamatsu Photonics, Hamamatsu City, Japan, and Carl Zeiss, Welwyn Garden City, UK.

\section{References}

Becskei A, Séraphin B \& Serrano L 2001 Positive feedback in eukaryotic gene networks: cell differentiation by graded to binary response conversion. EMBO Journal 20 2528-2535.

Berwaer M, Monget P, Peers B, Mathy-Hartert M, Bellefroid E, Davis JRE, Belayew A \& Martial JA 1991 Multihormonal regulation of human prolactin gene expression from $5000 \mathrm{bp}$ of its upstream sequence. Molecular and Cellular Endocrinology 80 53-64.

Biggar SR \& Crabtree GR 2001 Cell signalling can direct either binary or graded transcriptional responses. EMBO Journal 20 3167-3176.

Castano JP, Kineman RD \& Frawley LS 1996 Dynamic monitoring and quantification of gene expression in living cells: a molecular basis for secretory cell heterogeneity. Molecular Endocrinology 10 599-605.

Castro MG, Goya RG, Sosa YE, Rowe J, Larregina A, Morelli A \& Lowenstein PR 1997 Expression of transgenes in normal and neoplastic anterior pituitary cells using recombinant adenoviruses: long term expression, cell cycle dependency, and effects on hormone secretion. Endocrinology 138 2184-2194.

Craig FF, Simmonds AC, Watmore D, McCapra F \& White MRH 1991 Membrane permeable luciferin esters for assay of firefly luciferase in live intact cells. Biochemical Journal 276 637-641.

Davis JRE, McVerry J, Lincoln GA, Windeatt S, Lowenstein PR, Castro MG \& McNeilly AS 2001 Cell type-specific adenoviral transgene expression in the intact ovine pituitary gland after stereotaxic delivery: an in vivo system for long-term multiple parameter evaluation of human pituitary gene therapy. Endocrinology $142795-801$.

Frawley LS, Faught WJ \& Moomaw B 1994 Real time measurement of gene expression in living endocrine cells. Endocrinology 135 468-471.

Hartman ML, Pincus SM, Johnson ML, Matthews DH, Faunt LM, Vance ML, Thorner MO \& Veldhuis JD 1994 Enhanced basal and disorderly growth hormone secretion distinguish acromegalic from normal pulsatile growth hormone release. Journal of Clinical Investigation 94 1277-1288.

Hofland LJ, Velkeniers B, van Koetsveld PM, Hooghe-Peters EL \& Lamberts SWJ 1991 The relationship between growth hormone $(\mathrm{GH})$ messenger ribonucleic acid levels and hormone release from individual cells derived from human $\mathrm{GH}$-secreting pituitary adenomas. Clinical Endocrinology 34 5-11.

Hume DA 2000 Probability in transcriptional regulation and its implications for leucocyte differentiation and inducible gene expression. Blood 96 2323-2328.

Lee EJ, Anderson LM, Thimmapaya B \& Jameson JL 1999 Targeted expression of toxic genes directed by pituitary hormone promoters: 
a potential strategy for adenovirus-mediated gene therapy of pituitary tumours. Journal of Clinical Endocrinology and Metabolism $\mathbf{8 4}$ 786-794.

McFerran DW, Stirland JA, Norris AJ, Khan RA, Takasuka N, Seymour ZC, Gill MS, Robertson WR, Loudon ASI, Davis JRE et al. 2001 Persistent synchronised oscillations in prolactin gene promoter activity in living pituitary cells. Endocrinology 142 3255-3260.

McNally JG, Muller WG, Walker D, Wolford R \& Hager GL 2000 The glucocorticoid receptor: rapid exchange with regulatory sites in living cells. Science 287 1262-1265.

Nagai T, Sawano A, Park ES \& Miyawaki A 2001 Circularly permuted green fluorescent proteins engineered to sense $\mathrm{Ca}^{2+}$. PNAS 98 3197-3202.

Norris AJ, Stirland JA, McFerran DW, Seymour ZC, Spiller DG, Loudon ASI, White MRH \& Davis JRE 2003 Dynamic patterns of growth hormone gene transcription in individual living pituitary cells. Molecular Endocrinology 17 193-202.

Panda S, Antoch MP, Miller BH, Su AI, Schook AB, Straume M, Schultz PG, Kay SA, Takahashi JS \& Hogenesch JB 2002

Coordinated transcription of key pathways in the mouse by the circadian clock. Cell 109 307-320.

Rutter GA, Kennedy HJ, Wood CD, White MRH \& Tavare JM 1998 Real-time imaging of gene expression in single living cells. Chemistry and Biology 5 R285-R290.

Shang Y, Hu X, DiRenzo J, Lazar MA \& Brown M 2000 Cofactor dynamics and sufficiency in estrogen receptor-regulated transcription. Cell 103 843-852.

Shering AF, Bain D, Stewart K, Epstein AL, Castro MG, Wilkinson GW \& Lowenstein PR 1997 Cell type specific expression in brain cell cultures from a short human cytomegalovirus major immediate early promoter depends on whether it is inserted into herpesvirus or adenovirus vectors. Journal of General Virology 78 445-459.

Shorte SL, Leclerc GM, Vazquez-Martinez R, Leaumont DC, Faught WJ, Frawley LS \& Boockfor FR 2001 PRL gene expression in individual mammotropes displays distinct functional pulses that oscillate in a non-circadian temporal pattern. Endocrinology 143 1126-1133.

Smith-Arica J, Williams JC, Stone D, Smith J, Lowenstein PR \& Castro MG 2001 Switching on and off transgene expression within lactotrophic cells in the anterior pituitary gland in vivo. Endocrinology 142 2521-2532.

Southgate TD, Windeatt S, Smith-Arica J, Gerdes CA, Perone MJ, Morris I, Davis JRE, Klatzmann D, Lowenstein PR \& Castro MG 2000 Transcriptional targeting to anterior pituitary lactotrophic cells using recombinant adenovirus vectors in vitro and in vivo in normal and estrogen/sulpiride-induced hyperplastic anterior pituitaries. Endocrinology 141 3493-3505.
Stirland JA, Johnston JD, Cagampang FRA, Morgan PJ, Castro MG, White MRH, Davis JRE \& Loudon ASI 2001 Photoperiodic regulation of prolactin gene expression in the Syrian hamster by a pars tuberalis-derived factor. Journal of Neuroendocrinology 13 $147-157$.

Stone D, David A, Bolognani F, Lowenstein PR \& Castro MG 2000 Viral vectors for gene delivery and gene therapy within the endocrine system. Journal of Endocrinology 164 103-118.

Takasuka N, White MRH, Wood CD, Robertson WR \& Davis JRE 1998 Dynamic changes in prolactin promoter activation in individual living lactotrophic cells. Endocrinology 139 1361-1368.

Veldhuis JD \& Johnson ML 1986 Cluster analysis: a simple versatile, and robust algorithm for endocrine pulse detection. American Journal of Physiology 250 E486-E493.

Villalobos C, Faught WJ \& Frawley LS 1998 Dynamic changes in spontaneous intracellular free calcium oscillations and their relationship to prolactin gene expression in single, primary mammotropes. Molecular Endocrinology 12 87-95.

White MRH, Morse J, Boniszewski ZAM, Mundy CR, Brady MAW \& Chiswell DJ 1990 Imaging of firefly luciferase expression in single mammalian cells using high sensitivity charge coupled device cameras. Technique 2 194-201.

White MRH, Masuko M, Amet L, Elliott G, Braddock M, Kingsman AJ \& Kingsman SM 1995 Real-time analysis of the transcriptional regulation of HIV and hCMV promoters in single mammalian cells. Journal of Cell Science 108 441-445.

Windeatt S, Southgate TD, Dewey RA, Bolognani F, Perone MJ, Larregina AT, Maleniak TC, Morris ID, Goya RG, Klatzmann D et al. 2000 Adenovirus-mediated herpes simplex virus type-1 thymidine kinase gene therapy suppresses oestrogen-induced pituitary prolactinomas. Journal of Clinical Endocrinology and Metabolism 85 1296-1305.

Wu JC, Inubushi M, Sundaresan G, Schelbert HR \& Gambhir SS 2002 Optical imaging of cardiac reporter gene expression in living rats. Circulation 105 1631-1634.

Yamaguchi S, Kobayashi M, Mitsui S, Ishida Y, van der Horst GTJ, Suzuki M, Shibata S \& Okamura H 2001 View of a mouse clock ticking. Nature 409684

Zaccolo M, di Georgi F, Cho CY, Fang LX, Knapp T, Negulescu PA, Taylor SS, Tsien RY \& Pozzan T 2000 A genetically encoded, fluorescent indicator for cyclic AMP in living cells. Nature Cell Biology 2 25-29.

Received 6 February 2003

Accepted 21 March 2003 